\title{
A Individuação Fotográfica
}

\section{The Photographic Individuation}

\section{Resumo:}

Neste artigo relacionamos a produção fotográfica com os processos de individuação teorizados por Gilbert Simondon. A fotografia é considerada como um processo com diversas fases ou individuações, sejam elas físicas, psíquicas ou coletivas. A partir de uma individuação irreversível produzida pelo artefato da máquina fotográfica, outras individuações são possíveis e moduladas pelo discurso e por singularidades de cada sujeito. Os discursos relacionados à fotografia são entendidos como individuações coletivas suscetíveis ao regime de verdade de determinada época e sociedade. Propomos assim abordar o processo fotográfico levando em consideração diversos níveis de individuação e o uso de conceitos não estáticos, como a informação segundo Simondon e discurso conforme Foucault.

Palavras-chave: Fotografia. Individuação. Gilbert Simondon. Discurso.

\section{Abstract:}

In this article we relate photographic production with the individuation process theorized by Gilbert Simondon. Photography is regarded as a process with different phases or individuations, whether physical, psychological or collective. Starting from the irreversible individuation produced by a camera artifact, other individuations are possible and modulated by the discourse and singularities of each subject. The discourses related to photography are understood as collective individuations susceptible to the regime of truth of a particular time and society. We propose to approach the photographic process taking into account different levels of individuation and the use of concepts that are not static, as information according to Simondon and discourse as Foucault.

Keywords: Photography. Individuation. Gilbert Simondon. Discourse.

MAURENTE, Vanessa; DIEHL, Rafael. A individuação fotográfica. Informática na Educação: teoria \& prática, Porto Alegre, v. 15, n. 1, p. 131-137, jan./jun. 2012.

\section{Vanessa Maurente}

Pontifícia Universidade Católica do Rio Grande do Sul

Rafael Diehl

Centro Universitário UNIVATES

\section{Introdução}

N este artigo relacionamos a produção fotográfica com a teoria da individuação proposta por Gilbert Simondon, na qual a abordagem ontológica dos seres deixa de se concentrar no indivíduo já constituído para pôr ênfase no que o autor chama de processos de individuação. Aproximaremos a complexidade epistemológica da fotografia à ideia de que os processos de individuação presentes nos vários momentos e usos da fotografia podem ser pensados como fases de um sistema que engloba objetos físicos, máquinas, pensamentos e discursos. Isso permite-nos pensar a fotografia como processo que envolve não apenas uma individuação física identificada ao artefato da máquina fotográfica, mas que também guarda um potencial de novas individuações relacionadas aos domínios psíquico e coletivos operados por cada sujeito. Desse modo, poderemos relacionar tais domínios à conceituação de discurso desenvolvida por Michel Foucault. 


\section{Processos de Individuação}

A partir de uma ideia ampla de indivíduo que inclui objetos, fases de seres vivos, fases de seres técnicos, pensamentos, coletivos Gilbert Simondon busca construir uma teoria da ontogênese através dos processos de individuação. De acordo com Simondon (2009), tem-se estudado os processos de individuação a partir do indivíduo, quando se deveria fazer o caminho inverso, ou seja, estudar os indivíduos a partir dos processos de individuação. Pois o indivíduo deveria ser compreendido como uma realidade relativa, uma fase do ser à qual se antecede uma realidade pré-individual e metaestável. Iremos trazer para discussão algumas noções desse autor, necessárias para entender o que ele chama de individuação.

De acordo com Simondon (2009), a individuação não podia ser pensada adequadamente porque somente se conhecia o equilíbrio estável, que corresponde ao mais baixo nível de energia potencial. Para analisar os processos de individuação, Simondon afirma ser necessário entender o equilíbrio metaestável, que inclui o devir e permite, assim, que o ser se individue. No caso da individuação dos seres físicos há uma resolução da metaestabilidade, ou seja, eles se individuam de uma só vez, encerrando o potencial pré-individual do sistema e deixando atrás de si a dualidade indivíduo e meio. No caso dos seres vivos, a mesma ideia de metaestabilidade é utilizada para pensar a individuação, mas esta não se produz mais de uma maneira definitiva. Existiria para o vivo também uma origem absoluta (da individuação orgânica), mas essa seria sempre acompanhada de uma individuação perpétua - o que é a própria vida. O vivo seria o modelo fundamental do devir, pois conserva em si uma atividade incessante, não sendo somente "resultado de individuação, como o cristal ou a molécula, mas também teatro de individua- ção" (SIMONDON, 2009, p. 110). No caso dos vivos, haveria uma espécie de ressonância interna, caracterizada pela metaestabilidade das condições de vida.

Sendo assim, o vivo seguiria se individuando, modificando a si próprio, inventando novas estruturas internas como resultado da existência: "o indivíduo vivo é sistema de individuação, sistema individuante e sistema individuando-se" (SIMONDON, 2009, p. 105). Isto o faz diferente do indivíduo físico, que teria um passado fixo, uma constituição encerrada e radical. Pelo contrário, "o vivo é contemporâneo de si próprio em todos os seus elementos" (SIMONDON, 2009, p. 105). A compreensão inerente a isto é a de que um indivíduo nem sempre esgota seu potencial pré-individual, podendo carregar consigo um regime de metaestabilidade que garanta novas individuações. Já o psiquismo, para Simondon, seria o seguimento da individuação vital em um ser que, "para resolver sua própria problemática, é obrigado a intervir, por sua própria ação, como elemento do problema, como sujeito (SIMONDON, 2009, p. 106). Por sua vez, o sujeito em Simondon seria, ao mesmo tempo, a unidade do ser e uma dimensão do mundo, enquanto ser que representa sua ação.

Para Simondon (2009), o ser psíquico não pode resolver, sozinho, sua problemática. Ele também carrega em si um potencial pré-individual, que o diferencia do indivíduo e o coloca em um sistema de relações do mundo e do sujeito e, além disso, consiste em uma forma de individuação coletiva. Sendo assim, as individuações psíquica e coletiva são recíprocas e permitem pensar numa esfera transindividual, que "contribui para a explicação da unidade sistemática da individuação interior (psíquica) e da individuação exterior (coletiva)" (SIMONDON, 2009, p. 107). O transindividual não é nem o social bruto, nem a esfera interindividual, mas uma operação de individuação que 
contém sua própria metaestabilidade. Assim, o coletivo intervém como resolução da problemática individual, sendo que parte da realidade coletiva está contida em um indivíduo. Porém, esta parte é realidade pré-individual e não individuada.

A proposta simondoniana consiste em estudar os modos de individuação a partir do ser em conformidade com o devir e não como um indivíduo substancializado que vive em um mundo estranho a ele. Isto significa estudar as formas de individuação nos níveis físico, vital e psicossocial. Estes três níveis extrapolam a individuação nos vivos e fazem de sua teoria uma ontogênese relativa a objetos, máquinas, sujeitos, pensamentos, percepções, coletivos e conhecimento.

Para entender a individuação, Simondon (2009) propõe que se substitua a noção de forma pela de informação. De acordo com este autor, a antiga concepção de forma excluía a possibilidade de um sistema metaestável, conhecendo somente o equilíbrio estável. Por outro lado, a informação não se refere a uma unidade, mas sempre a duas ordens distintas:

[...] a informação, quer ao nível da unidade tropística, quer ao nível do transindividual, jamais é depositada em uma forma que pode ser dada; ela é a tensão entre dois reais díspares, a significação que surgirá quando uma operação de individuação descobrir a dimensão segundo a qual dois reais díspares podem tornar-se sistema (SIMONDON, 2009, p.109).

A informação nunca é, portanto, uma coisa dada, nunca é um termo e não tem uma identidade. Ela é inerente a uma problemática e supõe a tensão de um sistema do ser, ou seja, supõe um estado pré-individual do qual ela se torna, sempre no presente e pelo encontro de díspares, fórmula organizadora. A informação é uma exigência de individuação, o sentido segundo o qual um sistema se individua, pois ela aparece como relação entre as operações de individuação.

\section{Fotografia e discurso}

A relação entre fotografia e discurso pode ser pensada a partir de sua posição híbrida, principalmente no que se refere à dicotomia natureza e cultura. Alguns exemplos sobre os modos de utilização da fotografia na ciência, nas artes e na política podem nos ajudar a localizar em que nível das individuações fotográficas os discursos - relacionados ao verdadeiro, ao belo - se situam como operadores no processo. Utilizamos o conceito de discurso a partir de Michel Foucault. Para este autor (FOUCAULT, 1997), um discurso seria um conjunto de enunciados que se estabelecem de acordo com regras, enunciados e objetos que responderiam a um regime próprio e autônomo de formação, que o autor chama de formações discursivas. Essas formações se efetuam mediante condições de possibilidade de surgimento, existência e transformação. A noção de formação discursiva nos permitiria falar em um discurso científico, artístico, religioso, médico ou psicológico como articulações passíveis de reconfigurações pela coexistência com outros discursos. Dessa forma, as formações discursivas perfilar-se-iam entre si, transformando-se e definindo-se nos limites daquilo que podem ser em cada momento, através de práticas articuladas de forma a responder às exigências de determinado contexto histórico.

Quando o estatuto da arte é questionado em razão do surgimento da fotografia, podemos identificar um movimento no qual a relação entre participação humana e o valor da arte é trazido à questão, e que persistirá de certa maneira até hoje em diversas nuances sobre o estatuto da fotografia, situada entre a arte e ciência. Ainda hoje uma imagem fotográfica 
pode ser considerada uma reprodução - muitas vezes mais fiel do que o próprio olho - de uma realidade. Este é o caso das fotomicrografias utilizadas na física, química e biologia, consideradas como formas de acesso às características visuais de seres ou elementos microscópicos. Outras técnicas também são utilizadas com a mesma função, como a implantação de câmeras em regiões de difícil acesso a fim de fotografar animais raros e seu modo de vida.

Ao mesmo tempo em que a fotografia é tomada como uma ferramenta de "prova" no campo jurídico ou na biologia, ela poderá ser considerada um objeto artístico e a função realística será deixada de lado por uma discussão a respeito do autor de uma obra. Além disso, uma foto jornalística pode incluir essas duas considerações - natureza do que aparece na imagem e autoria do fotógrafo passando a uma terceira discussão, ética, a respeito daquilo que se faz interessante, moral, importante de ser fotografado. Surgem as perguntas sobre quem fotografou, porque e para quê. Questiona-se a posição do fotógrafo - está fazendo uma denúncia ou sendo conivente - quando a imagem traz cenas de sofrimento. Além disso, a imagem pode ser apenas uma parte a mais do espetáculo que se tornou a vida particular com a utilização massiva dos meios de compartilhamento via internet. Ou, também, o registro obsessivo de experiências da vida como viagens, festas e outros momentos, que passam a ganhar legitimidade e importância pela quantidade de fotos que concentram.

De acordo com Foucault (2004), os confrontos entre diferentes formas de saber implicam também relações de poder. Tais relações se estabelecem por jogos através dos quais se produzem efeitos de verdade em coisas que não são, em si, nem verdadeiras, nem falsas. Esta noção do que é verdadeiro e do que é falso ocorre em um processo de lutas, de confrontos e de resistências e passa a definir as possibilidades de subjetivação de um determinado momento histórico. Os regimes de verdade correspondem justamente a estas condições de possibilidade que fazem com que diferentes discursos possam se atravessar. Por exemplo, a utilização de fotos para a área jurídica, direcionando decisões sobre infrações ou crimes, pode ser pensada como um uso particular da fotografia relacionada ao discurso da ciência, mas que nem sempre fez parte do modo de resolução de litígios na história dos conflitos humanos.

Essa diversidade de usos e atravessamentos discursivos colocam a fotografia como um objeto especial na produção de conhecimento, principalmente nas ciências humanas onde os limites da formalização do conhecimento se misturam com os usos da linguagem e dos discursos. Nas ciências humanas a fotografia vem sendo utilizada como metodologia de pesquisa das mais diversas formas, que podem ir desde uma função mais ilustrativa - característica da antropologia visual mais tradicional - até proposições de intervenção em campo através da produção de imagens (TITTONI, 2004, DIEHL, 2007, DIAS, 2009, OLIVEIRA, 2009, SILVA, 2009, MAURENTE, 2010). Isso nos leva a pensar que a fotografia se encontra em um interstício no campo epistemológico, sendo capaz de servir como objeto de diferentes formações discursivas e fazer efeito no campo da arte, da ciência "dura", da filosofia, da comunicação, etc. Nosso objetivo não consiste em chegar a uma conclusão a respeito da fotografia, mas tomar justamente esta complexidade, esta condição tangente e processual como potência de análise em diversos campos.

\section{Fases do fotografar}

Considerar a fotografia não apenas em sua manifestação mais comum como imagem im- 
pressa ou visualizada em pixels, mas como um sistema no qual variadas fases podem ser distinguidas requer que possamos determinar os distintos níveis de individuação que identificam o fotografar. Nesse sentido, uma fotografia impressa ou revelada em papel é um indivíduo físico que não pode ser tomado de forma isolada em relação a todo o processo do fotografar. O uso de suportes digitais que permitem transformar uma fotografia codificada para ser impressa em diversos materiais nos encaminha ao artefato técnico central da fotografia que é a máquina fotográfica. Podemos encontrar nesse artefato algumas pistas sobre a complexidade epistemológica da fotografia, pois ele produz um objeto híbrido, no sentido de não poder ser reduzido apenas aos suportes onde as fotografias estão impressas, mas colocam a individualidade do fotografar numa zona de transição entre a matéria e a representação.

$\mathrm{Na}$ fotografia analógica temos uma individuação física que se realiza de uma só vez a partir de uma marca luminosa em sais de prata que pode, posteriormente, ser revelada ou modificada em seu suporte fílmico. Um processo distinto, porém semelhante no sentido da individuação, aconteceria no caso da fotografia digital, quando se produz, de um só golpe, um código numérico que poderá se atualizar - aí sim, de diferentes formas - em objetos técnicos. Essa diferença nos permite considerar que há, na produção fotográfica, uma individuação que se dá de uma só vez e que se refere ao instante em que o obturador permite criar uma estrutura que identifica a fotografia com seu momento de produção. Por mais que ela possa ser individuada em diversos suportes conforme sua codificação digital, há uma irreversibilidade que marca todo o processo fotográfico.

Isso não quer dizer que todo o potencial metaestável da fotografia foi eliminado, mas que, graças à particularidade do artefato da máquina fotográfica, as condições pré-individuais presentes no momento da produção da fotografia não se repetirão da mesma forma. Nesse sentido, as condições pré-individuais presentes em cada fase do fotografar não são as mesmas, mas podemos identificar um núcleo individuante que modulará as outras individuações possíveis a partir das fotografias produzidas e do potencial pré- individual em cada nível.

A condição híbrida da fotografia pode ser entendida quando ela é considerada como objeto já individuado, no sentido de ser um indivíduo resultante de um artefato técnico que produz uma estrutura bidimensional passível de ser lida e individualizada em diversos suportes. Isso permite que ela seja modulada e module discursos relacionados não apenas ao seu estatuto em relação ao conhecimento, mas também a seu conteúdo como matéria simbólica. Dessa maneira, ela pode ser identificada com diversos modos de relação entre uma representação (a fotografia como objeto individuado) e seu referente, pois comportaria, ao mesmo tempo, uma identidade icônica (relação de semelhança com o referente), simbólica (relação por convenção com o referente) e indiciária (relação de contiguidade física com o referente) (DUBOIS, 1994).

Podemos partir do conceito de informação em Simondon (2009) para pensar a fotografia e seu processo como um conjunto de individuações que operam em diferentes níveis de realidade. A articulação entre as diversas fases do fotografar e o potencial de metaestabilidade presente em cada nível podem ser melhor visualizados na relação fotografia - discurso experiências singulares. A particularidade da individuação fotográfica advinda da operação da máquina fotográfica, ou seja, um indivíduo que não pode ser reduzido apenas à matéria ou à forma, vai modular as outras individuações 
relacionadas a tal objeto. Da mesma maneira que na noção de informação para Simondon, uma fotografia não pode ser identificada a uma forma dada, pois ela precisa de indivíduos vivos que a individuem no nível perceptivo singular e num contexto coletivo que podem ser relacionados ao que chamamos de discursivo. Além disso, quando um sujeito visualiza uma fotografia e produz individuações perceptivas singulares, elas também estão atravessadas pelos discursos e individuações coletivas relativas ao estatuto da fotografia.

Essa posição complexa do objeto fotográfico vai estar articulada com os regimes de verdade, que podem ser entendidos como estabilidades de individuações coletivas no que se refere ao conhecimento. Por esse motivo, o ser da fotografia não pode ser reduzido ao indivíduo produzido pelo artefato da máquina fotográfica, mas englobar o conjunto de máquinas, suportes e códigos que permitem que ela possa ser impressa, transmitida e modificada em sua individuação física.

Pela possibilidade de significar coisas distintas, a fotografia está relacionada tanto aos regimes de verdades quanto às individuações perceptivas singulares. Ao mesmo tempo, ela é uma só coisa (física) individuada, mas também um conjunto heterogêneo de experiências e individuações em níveis perceptivos e coletivos que a modulam de acordo com discursos e regimes de verdade. Isto faz dela um objeto particular, que desdobra diversas concepções e infinitos olhares a partir de uma única imagem, produzida em relação com diferentes discursos sobre o conhecimento e a partir da singularidade do encontro entre um sujeito e um objeto técnico.

\section{Considerações finais}

Os diversos usos e entendimentos da fotografia mostram que considerá-la como um objeto estável nos encaminha a problemas de ordem epistemológica e política, pois a particularidade de seu processo de individuação articula dimensões que, em geral, são tratadas por áreas e disciplinas distintas. Considerar a metaestabilidade presente no processo do fotografar exige levar em consideração os potenciais pré-individuais que estão presentes nos diversos níveis de individuação. Esses potenciais pré-individuais permitem um entendimento sobre a relação do discurso com a fotografia pois, tanto no nível das individuações coletivas como no nível psíquico, é por uma operação de transdução que a experiência singular de cada sujeito está articulada com os discursos e os regimes de verdade que compõem a complexidade de tal objeto. Esses potenciais são imprevisíveis, mas não nos tiram a responsabilidade de entender os limites do uso e as implicações da fotografia em campos onde as relações humanas tem caráter produtor de realidades. São esses campos transindividuais, que concentram discursos, sujeitos e imagens, um espaço promissor de estudos e investigações para um entendimento não apenas do processo do fotografar, mas de todos os processos nos quais a vida humana está constitutivamente relacionada. 


\section{Referências}

DIAS, D. A intervenção fotográfica no campo do trabalho da assistência social. In: TITTONI, J. (Org.) Psicologia e Fotografia: experiências em intervenções fotográficas. Porto Alegre: Dom Quixote, 2009.

DIEHL. R. Do mapa à fotografia: planografias de um espaço louco. Dissertação de Mestrado. Programa de Pós-graduação em Psicologia Social e Institucional/UFRGS, Porto Alegre, Editora da UFRGS, 2007.

DUBOIS, P. O ato fotográfico e outros ensaios. Campinas, Papirus, 1994.

FOUCAUlt, M. A arqueologia do saber. Rio de Janeiro, Forense Universitária, 1997.

FOUCAULT, M. A ética do cuidado de si como prática da liberdade In: Ditos e Escritos V: Ética, Sexualidade e Política, p.264 a 287. São Paulo, Forense Universitária, 2004.

MAURENTE, V. Imagens do hospício vazio: fotografia, pesquisa e intervenção. Tese de doutorado: Programa de Pós-graduação em Informática na Educação/UFRGS. Porto Alegre: Editora da UFRGS, 2010.

OLIVEIRA, R. Entre formações e in(ter)vençoes fotográficas - produções na assistência jurídica universitária. In: TITTONI, J. (Org.). Psicologia e Fotografia: experiências em intervenções fotográficas. Porto Alegre: Dom Quixote, 2009.

SILVA, P. A arte de pesquisar o trabalho no território das cidades: a rua como "lugar da questão". In: TITTONI, J. (Org.). Psicologia e Fotografia: experiências em intervenções fotográficas. Porto Alegre: Dom Quixote, 2009.

SIMONDON, G. La individuación. Buenos Aires: Ediciones La Cebra y Editorial Cactus, 2009.

TITTONI, J. Saúde mental, trabalho e outras reflexões sobre economia solidária. In: MERLO, A. (Org.) Saúde e Trabalho no Rio Grande do Sul: realidade, pesquisa e intervenção. 1 ed. v.1 p.65-93 Porto Alegre. Editora da UFRGS, 2004.

Recebido em: 26 de setembro de 2011

Aprovado para publicação em: 28 de novembro de 2011

\section{Vanessa Soares Maurente}

Docente na Pontifícia Universidade Católica do Rio Grande do Sul e na Escola Superior de Administração, Direito e Economia. Porto Alegre/RS, Brasil. E-mail: vanessamaurente@yahoo.com.br

\section{Rafael Dieh!}

Professor convidado do Centro Universitário UNIVATES, Porto Alegre/RS, Brasil, E-mail: diehlrafael@yahoo. com.br 